\title{
Indicator role of the ontogenetic structure of rare plant cenotic populations in the assessment of the ecological state of species under anthropogenic pressure (for example, Rindera tetraspis Pall)
}

\author{
Valentina Ilyina ${ }^{1, *}$, and Anna Mitroshenkova ${ }^{1}$ \\ ${ }^{1}$ Samara State University of Social Sciences and Education, 443090, Antonov-Ovseenko Str., 26, \\ Samara, Russia
}

\begin{abstract}
The study of population structure, including ratios in different ontogenetic groups of individuals, provides unique information for the development of express methods of determining the ecological state of natural complexes. Data on population structure, dynamics of population indicators and other bioecological features allow to determine more precisely the need for protection of different species at regional and more global levels. The purpose of this research is to determine the ontogenetic structure of natural populations of rare plant species. The example of Rindera tetraspis Pall. was used to establish changes in ontogenetic structure of local populations under anthropogenic pressure on species' habitats (on the territory of the Middle Volga basin, Russia). A decrease in the ability to self-sustain the number of individuals and aging of the population at cattle grazing and steppe fires have been revealed.
\end{abstract}

\section{Introduction}

Protection of rare plant species and justification for this protection in the flora of specific regions of Russia and the world is carried out on the basis of various approaches. The results of ecobiological analysis of local lists of species found on a relatively small area are mainly used [1]. This approach makes it possible to determine the percentage of rare representatives to the total number of species, but does not allow estimating the contribution of these plants to plant groups. Thus, researchers usually give indications on the proportion of rare species among typical plants of the region and their protection is justified by the number of individuals. Numbers are often determined in a more intuitive way and relatively large and visible generative individuals are recorded (in relation to herbaceous plants in almost all cases).

The methods of population-ontogenetic direction applied in modern ecology and botany provide an opportunity to define a wider spectrum of questions about species and population

*Corresponding author: 5iva@mail.ru,mds_mitri4@mail.ru 
features of rare flora representatives, including characteristics of ontomorphogenesis, life expectancy, stability of individuals and their combination to adverse and/or changing conditions of habitats $[2,3]$.

We carry out a multi-dimensional study of plant cenopulations (CPU) in the Middle Volga basin. The research includes detection of ontogenesis stages and determination of their duration, anatomical and morphological features, spatial, ontogenetic, vitality structure of cenopopulations, seed productivity of individuals, reaction to changes in living conditions, adaptation mechanisms of organism and population level to anthropogenic impacts, stability and lability of local populations.

Ontogenetic structure is one of the leading population characteristics having indicator significance in determining the state of cenopopulations in modern conditions on a certain territory $[4,5]$. It is determined by the ratio of individuals of different ages and is expressed as an ontogenetic spectrum.

\section{Materials and Methods}

To identify the population structure we used population-ontogenetic research methods [4-9].

A plant cenopopulation includes all individuals of a species within the same plant community. The object of study is not a single plant, but a cenotic population of plants. In order to study the biology of a species, it is necessary to take into account the duration of complete ontogenesis as the total lifetime of individuals in all ontogenetic states.

In determining the age structure of the cenopopulation according to standard criteria (Rabotnov, 1950; Uranov, 1975), the following age states were taken into account: seedling $(\mathrm{p})$, juvenile $(\mathrm{j})$, immature (im), virgin $(\mathrm{v})$, young generative $\left(\mathrm{g}_{1}\right)$, medium generative $\left(\mathrm{g}_{2}\right)$, old generative $\left(\mathrm{g}_{3}\right)$. Each specific cenopopulation has its own age spectrum. Based on the data obtained, the ontogenetic (age) spectra of the cenopopulations were constructed. Ontogenetic (age) spectrum of cenopopulations was created from the obtained data.

The main indicators of the dynamics of ontogenetic structure of plant species populations are the replacement index $\left(\mathrm{I}_{\mathrm{rep}}\right)$, recovery index $\left(\mathrm{I}_{\mathrm{rec}}\right)$ and age index $(\Delta)$.

The recovery index estimates the number of descendants in a population per plant of the generative period. The replacement index in cenopopulations reveals the number of descendants per adult plant of generative or post-generative period.

The ontogenetic structure defines demographic indicators of populations, and both this structure and these indicators largely determine the viability of the population system, its self-recovery, self-maintenance, stability and lability.

The research area is located in the High Trans-Volga region. The climate is continental, with total annual precipitation of $400-600 \mathrm{~mm}$. The soils in this area are typical carbonate and residual-carbonate chernozems, sometimes washed away up to its parent rock.

Rindera tetraspis Pall. is a perennial root herbaceous plant with a straight stem up to 30 $\mathrm{cm}$ high (Fig. 1). It covers the south-east of European Russia, Ukraine, Crimea, Ciscaucasia and Western Transcaucasia, the south-east of Western Siberia and the north of Central Asia [10].

Cenopopulations of the species were studied from 2014 to 2020. 
Fig. 1. Rindera tetraspis Pall. [10].

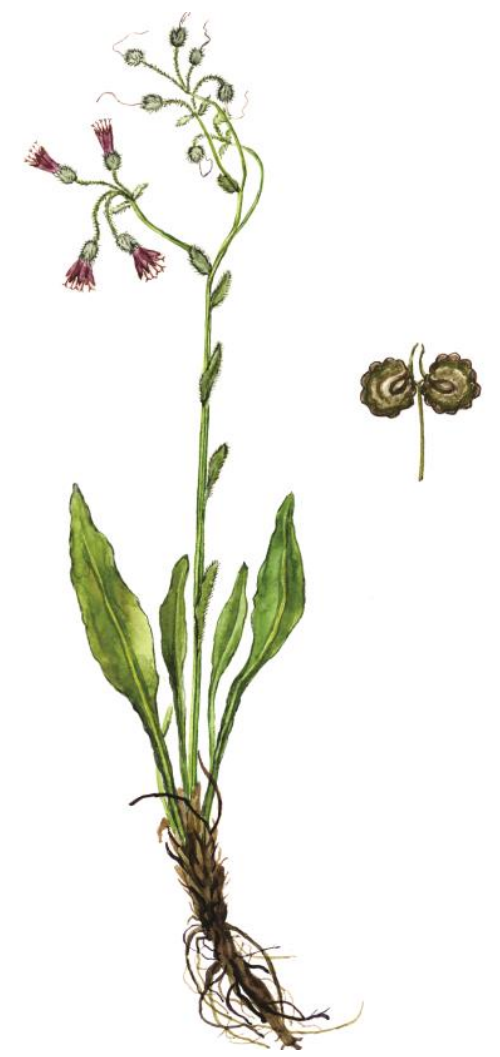

\section{Results and Discussion}

The data on peculiarities of ontogenetic structure of cenopopulations of rare species are presented in Tables 1 and 2. As an example, the results of research on the ontogenetic structure of the Rindera tetraspis Pall. cenotic populations are given.

Table 1. Ontogenetic spectra of cenopopulations.

\begin{tabular}{|c|c|c|c|c|c|c|c|c|c|}
\hline CPU no. & $\mathrm{p}$ & $\mathrm{j}$ & $\mathrm{im}$ & $\mathrm{v}$ & $\mathrm{g} 1$ & $\mathrm{~g} 2$ & $\mathrm{~g}_{3}$ & $\mathrm{ss}$ & $\mathrm{s}$ \\
\hline 1 & 0.0 & 2.7 & 6.6 & 12.4 & 30,6 & 20.6 & 22.5 & 4.6 & 0.0 \\
\hline 2 & 2.9 & 2.1 & 15.9 & 10.6 & 18.1 & 18.9 & 27.8 & 3.7 & 0.0 \\
\hline 3 & 0.0 & 3.1 & 6.2 & 13.1 & 25.7 & 24.8 & 23.1 & 4.0 & 0.0 \\
\hline 4 & 3.0 & 1.9 & 4.4 & 12.9 & 34.1 & 13.7 & 26.7 & 3.3 & 0.0 \\
\hline 5 & 1.6 & 5.7 & 9.5 & 14.8 & 22.3 & 22.9 & 18.5 & 4.7 & 0.0 \\
\hline 6 & 0.0 & 2.3 & 14.2 & 11.7 & 12.8 & 28.9 & 24.9 & 5.2 & 0.0 \\
\hline 7 & 1.5 & 3.7 & 18.5 & 6.2 & 20.4 & 24.1 & 20.4 & 5.2 & 0.0 \\
\hline 8 & 1,1 & 3.8 & 2.8 & 8.3 & 17.4 & 28.0 & 31.6 & 7.0 & 0.0 \\
\hline 9 & 0.0 & 2.2 & 3.3 & 14.3 & 25.7 & 22.9 & 30.7 & 0.9 & 0.0 \\
\hline $\begin{array}{c}\text { middle } \\
\text { value }\end{array}$ & 1.1 & 3.1 & 9.0 & 11.6 & 23.0 & 22.8 & 25.1 & 4.3 & 0.0 \\
\hline
\end{tabular}


Table 2. Demographic Parameters of cenopopulations.

\begin{tabular}{|c|c|c|c|}
\hline CPU no. & $\begin{array}{c}\text { Replacement } \\
\text { index (Irep) }\end{array}$ & $\begin{array}{c}\text { Recovery } \\
\text { index }\left(I_{\text {rec }}\right)\end{array}$ & $\begin{array}{c}\text { Age index } \\
(\Delta)\end{array}$ \\
\hline 1 & 0.28 & 0.29 & 0.41 \\
\hline 2 & 0.46 & 0.49 & 0.40 \\
\hline 3 & 0.29 & 0.30 & 0.42 \\
\hline 4 & 0.29 & 0.30 & 0.40 \\
\hline 5 & 0.46 & 0.50 & 0.37 \\
\hline 6 & 0.39 & 0.42 & 0.43 \\
\hline 7 & 0.43 & 0.46 & 0.39 \\
\hline 8 & 0.19 & 0.21 & 0.49 \\
\hline 9 & 0.25 & 0.25 & 0.44 \\
\hline middle value & 0.33 & 0.35 & 0.42 \\
\hline
\end{tabular}

The average ontogenetic spectrum of cenopopulations has a maximum at old generative plants $(25.1 \%)$, only a few young generative and mature generative plants (about 23.0 each) are inferior to this ontogenetic group. Subsenile individuals account for $4.3 \%$ of the total number of individuals. Generative plants (seedlings, juvenile, immature and virginyl plants) make a significant contribution to the cenopopulation structure - about $25 \%$.

Thus, the geographical cenopopulation of the Middle Volga basin is complete-membered. The average ontogenetic spectrum is characterized as right-sided, although it is rather conventional - other generative groups (young generative and mature generative) are almost equal in number of individuals.

Considering ontogenetic spectra of local populations, it is necessary to note some variety in structure. For example, the cenopopulation No. 2 has two peaks in the spectrum - $15.9 \%$ of immature plants and $27.8 \%$ of old generative plants. Young generative group of plants (34.1\%) prevails in the price population No. 4. Mature generative plants $(22.9 \%)$ predominate in the population No. 5, the second group is young generative plants $(22.3 \%)$.

The detected Rindera tetraspis cenopopulations were registered in the Middle Volga Basin under the steppe zone conditions. This area experiences rather high economic and recreational load on the preserved natural complexes. The vegetation cover is mainly affected by cattle grazing and steppe fires. Recreation in points far from towns and villages is almost minimal. A major problem for the preservation of rare steppe species is the complete destruction of natural complexes with an increase in arable land or construction.

The ontogenetic structure of Rindera tetraspis populations can serve as an indicator characteristic in the evaluation of the disturbance of natural complexes and their ecological condition.

High economic load is noted in the habitats of cenopopulations No. 8 and No. 9 (strong fires and intensive grazing). The reaction of the ontogenetic spectrum and population demographics associated with it indicates a general aging of cenopopulations (age index 0.44-0.49).

Other demographic indicators (replacement index, recovery index) show weak population replenishment by young individuals.

\section{Conclusions}

The ontogenetic structure of cenopopulations of rare plants can serve as an indicator characteristic for determining the condition of the vegetation cover or natural complexes in 
general. Knowing the regularities of changes in ontogenetic spectra, it is possible to conduct a rapid assessment of the degree of economic and recreational impact on phytocoenosis.

The studied rare representative of the steppe flora Rindera tetraspis is characterized by normal complete-membered cenopulations. Under the conditions of high load on species' habitats, aging is typical for cenopopulations. Demographic parameters point to the low ability of Rindera tetraspis to rejuvenate species populations and, consequently, to the low ability of Rindera tetraspis to grow in the Middle Volga basin.

The ontogenetic spectra of the majority of local populations of the given species point to its vulnerability in the region, unsatisfactory state under the conditions of anthropogenic load, weak adaptation to changing environment, weak competitiveness in phytocoenosis. Thus, the species demonstrates stenotopic characteristics.

\section{Acknowledgements}

This research project was state assignment of the Samara State University of Social Sciences and Education.

\section{References}

1. Red Book of the Russian Federation (plants and mushrooms) (2008)

2. G.Yu. Sofronov, N.V. Glotov, S.M. Ivanov, Analysis of ontogenetic spectra of populations of plants and lichens via ordinal regression, AIP Conf. Proc., 1651, 118127 (2015)

3. L. M. Abramova, V. N. Ilyina, A. N. Mustafina, O. A. Karimova, Biol. Bulletin, 46(10), 1199-1205 (2019)

4. A.A. Uranov, Biol. Nauki, 2, 7-34 (1975)

5. L.A. Zhukova, Russian Journal of Ecology, 32(30), 151-158 (2001)

6. J. L. Harper, J. White, Annual Review of Ecology and Systematics, 5, 419-463 (1974)

7. A. A. Sterk, Acta Botanica Neerlandica, 24, 315-337 (1975)

8. D. W. Schemske, Science, 227(4685), 405-406 (1985)

9. L.I. Vorontzova, L.B. Zaugolnova Population biology of steppe plants. The population structure of vegetation, Ed. J. White. III, 143-173 (1985)

10. Red Book of the Samara Oblast. Rare species of plants and fungi 1 (2017) 